\title{
Long-term natalizumab treatment is associated with sustained improvements in quality of life in patients with multiple sclerosis
}

\author{
John F Foley' \\ Kavita V Nair ${ }^{2}$ \\ Timothy Vollmer ${ }^{3}$ \\ Judith J Stephenson ${ }^{4}$ \\ Timothy Niecko ${ }^{5}$ \\ Sonalee S Agarwal ${ }^{6}$ \\ Crystal Watson ${ }^{6}$
}

'Rocky Mountain Multiple Sclerosis Clinic, Salt Lake City, UT, USA;

${ }^{2}$ Skaggs School of Pharmacy and Pharmaceutical Sciences, University of Colorado Denver, Aurora, CO, USA; ${ }^{3}$ Department of Neurology, University of Colorado School of Medicine, Aurora, CO, USA; ${ }^{4}$ HealthCore, Inc., Wilmington, DE, USA; ${ }^{5}$ Niecko Health Economics, Tierra Verde, FL, USA; ${ }^{6}$ Biogen, Cambridge, MA, USA
Correspondence: Crystal Watson Biogen, 225 Binney Street, Cambridge, MA 02। 42, USA

$\mathrm{Tel}+\mathrm{I} 7814645613$

Fax + I $86626 \mid 2808$

Email crystal.watson@biogen.com
This article was published in the following Dove Press journal:

Patient Preference and Adherence

16 June 2017

Number of times this article has been viewed

Background: Multiple sclerosis (MS) patients experience lower health-related quality of life (HRQoL) than the general population. In clinical trials, natalizumab significantly improved HRQoL and reduced relapse rates and disability progression in patients with relapsing MS. In a 1-year analysis of patients included in the current study, HRQoL improvement occurred within 3 months of natalizumab initiation and continued for 1 year thereafter. However, natalizumab's long-term efficacy in improving HRQoL has not been studied.

Methods: In this longitudinal, observational, single-arm US study, HRQoL and treatment satisfaction were evaluated in MS patients receiving intravenous natalizumab $300 \mathrm{mg}$ every 4 weeks in clinical settings. Patients completed surveys at baseline and every 6 months for 3 years and reported the following measures: Short Form-12 Version 2 (SF-12v2), Multiple Sclerosis Impact Scale (MSIS-29), and Treatment Satisfaction Questionnaire for Medication.

Results: In this study, 120 patients completed $\geq 3$ years of natalizumab treatment. Significant HRQoL improvements were evident from baseline to year 3 by increases in SF-12v2 Physical Component Summary (PCS) and Mental Component Summary scores $(P<0.01)$ and decreases in MSIS-29 physical and psychological scores $(P<0.0001)$. Patients with less physical disability (baseline Disease Steps [DS] 0-2) had significant improvement from baseline to year 3 in SF-12v2 PCS $(P<0.05)$ and MSIS-29 physical scores $(P<0.05)$. Physical HRQoL outcomes in patients with baseline DS 3-6 remained stable over 3 years. Treatment satisfaction increased significantly from baseline to year $1(P<0.0001)$ and was maintained in the following 2 years.

Conclusion: Patients reported physical and psychological HRQoL improvements over 3 years of natalizumab treatment, supporting the long-term efficacy of natalizumab in real-world settings. Lower baseline disease activity and earlier treatment were related to better outcomes, indicating the importance of starting natalizumab early in the disease course. Treatment satisfaction increased after natalizumab initiation and remained high over 3 years of treatment.

Keywords: relapsing multiple sclerosis, natalizumab, health-related quality of life, patientreported outcome, long-term efficacy

\section{Introduction}

Multiple sclerosis (MS) is a chronic inflammatory disorder of the central nervous system that is associated with a range of devastating symptoms. ${ }^{1}$ The accumulation of disability that occurs in most patients with MS can have a detrimental effect on quality of life. ${ }^{2,3}$ The quality of life of patients with MS is not only lower than that of the general population ${ }^{4,5}$ but also lower than that of patients with other chronic conditions such as rheumatoid arthritis and inflammatory bowel disease. ${ }^{6}$ 
Current treatments for MS focus on relieving the inflammation underlying the disease activity. However, measuring the effects of treatment on quality of life offers important supporting information on clinical effectiveness. As quality of life and treatment satisfaction can only be accurately assessed by the individual patient, the use of patient-reported outcome (PRO) measures is necessary to understand the impact of the disease. Both general and disease-specific PRO instruments have been validated for use in patients in MS. The inclusion of PRO measures in clinical trials for MS therapies can provide a more complete assessment of the effects of treatment.

Natalizumab is a disease-modifying therapy used to treat relapsing multiple sclerosis (RMS). In the phase 3 clinical trial AFFIRM, natalizumab-treated patients exhibited a reduction in annualized relapse rate, risk of disability progression, and disease activity measured by magnetic resonance imaging over 2 years. ${ }^{7}$ In addition, natalizumab treatment was associated with significant improvement in physical disability over 2 years. ${ }^{8}$ Over the course of this 2 -year trial, natalizumab-treated patients also experienced significant improvements in physical and mental health-related quality of life (HRQoL), as assessed by the Short Form-36 (SF-36) survey, whereas placebo-treated patients exhibited worsening of HRQoL. 5

In clinical settings, natalizumab-treated patients showed significant improvements in physical and psychological aspects of HRQoL, and also reported reductions in fatigue and cognitive dysfunction. ${ }^{9}$ These treatment effects were observed as early as 3 months after therapy initiation and were sustained for $\geq 1$ year. However, the long-term effects of natalizumab on HRQoL have not been determined.

This study focuses on the effects of natalizumab treatment over 3 years on HRQoL and treatment satisfaction. Moreover, we investigated whether baseline disease level, years since MS diagnosis, or age at the time of natalizumab treatment initiation influenced the effect of treatment on HRQoL.

\section{Materials and methods Study design}

A longitudinal, observational, single-arm study was conducted in the US to evaluate HRQoL and treatment satisfaction in patients with MS who received natalizumab $300 \mathrm{mg}$, administered intravenously, every 4 weeks. The methodology of this study has previously been published. ${ }^{9}$ Briefly, patients were recruited to treatment through the manufacturer's restricted drug distribution program - the Tysabri Outreach Unified Commitment to Health (TOUCH). Eligible patients were $\geq 18$ years old, had a diagnosis of RMS, and had been prescribed natalizumab. Patients had not received their first infusion of natalizumab prior to entering the study. Patients understood English and were able to provide verbal telephone consent to participate in the study and complete the assessments. Recruitment began in July 2008 and ended in January 2009; the study was completed in July 2013. Patients completed a 25-minute telephone or internet survey before starting natalizumab (baseline) treatment and within 1 month after the 3rd, 6th, 12th, 18th, 24th, 30th, and 36th infusions. For all surveys conducted after the first year of treatment, retention rates from one survey to the next were consistently $\geq 80 \%$. Surveys were coordinated by HealthCore, Inc. (Wilmington, DE).

The protocol, recruitment, consent, and survey procedures were approved by the New England Institutional Review Board. All patient data were handled in compliance with the regulations of the US Insurance Portability and Accountability Act of 1996.

\section{PRO assessments}

During each survey, patients completed PRO assessments evaluating HRQoL, level of disability, functional status (ie, ability to carry out normal daily activities), fatigue, cognitive status, and treatment satisfaction. PRO instruments were chosen based on the length of time required for completion so as to limit respondent burden. Information on demographics and disease characteristics was collected at the start of the study.

\section{Short Form- 12 Version 2 (SF-I2v2)}

The SF-12v2 is a psychometrically validated, reliable, generic HRQoL instrument that assesses the physical and mental health of patients. ${ }^{10,11}$ It is a short form of the SF-36, which is frequently used in clinical trials. The SF-12v2 consists of 12 questions from the SF-36 that evaluate the same eight health domains as the SF-36: physical function, the role-physical, bodily pain, general health, vitality, social function, the role-emotional, and mental health. The Physical Component Summary (PCS) and Mental Component Summary (MCS) scores are norm-based scores ranging from 0 to 100 calculated from the responses to the 12 questions using scoring software. In the general US population, the mean score is 50 , with a standard deviation (SD) of $10 .^{10}$ Higher scores indicate better HRQoL. ${ }^{11}$ In this study, no change (ie, remaining stable over the course of the study) or an increase in score was considered a positive outcome for the patient, and patients with an improvement of at least 5 points $(0.5 \mathrm{SD})$ from baseline in MCS or PCS scores were considered responders. ${ }^{12}$ 


\section{Multiple Sclerosis Impact Scale (MSIS-29)}

The MSIS-29 is a psychometrically validated HRQoL measure that assesses the disease-specific physical and psychological impact of MS from the patient's perspective. ${ }^{13,14}$ The survey consists of 29 questions. Twenty questions assess the impact of MS in terms of its effect on mobility and self-care, and nine questions assess the effect of MS on anxiety and depression. Summary physical and psychological scores are calculated on a scale of $0-100$, with lower summary scores corresponding to better HRQoL. In this study, no change (ie, remaining stable over the course of the study) or a score decrease was assumed to be a positive outcome for the patient, and patients with an improvement of 10 points from baseline in at least one score category were considered responders. ${ }^{9}$

\section{Treatment Satisfaction Questionnaire for Medication (TSQM-9)}

The TSQM-9 is a psychometrically validated measure of patient satisfaction with medication. ${ }^{15-17}$ The TSQM-9 comprises three subscales that assess the patient's perception of medication effectiveness, convenience, and global satisfaction. The effectiveness subscale assesses the patient's satisfaction with the ability of the medication to treat the condition and relieve symptoms and the length of time it takes for the medication to start working. The convenience subscale addresses the convenience of administration and ease of planning and following a schedule. The global satisfaction subscale gauges a patient's confidence that the medication is a good thing and that the advantages of taking it outweigh the disadvantages. ${ }^{16}$ Each TSQM-9 subscale consists of three items, with responses measured on a Likert scale ranging from 1 (low) to 7 (high). Subscale scores were transformed to a range from 0 to 100 , with higher scores indicating greater satisfaction.

\section{Functional Status (FS)}

The FS scale consists of a single question with five responses ranging from FS1 (no impairment) to FS5 (high impairment). ${ }^{9}$ The scale assesses the ability of patients to perform activities of daily living and is adapted from a self-report questionnaire that measures neurological impairment in patients with MS. ${ }^{18}$

\section{Disease Steps (DS)}

The DS scale, the predecessor to the Patient-Determined Disease Steps scale, is a physician-reported outcome instrument that was developed to provide a simple assessment of MS disability to follow patients over time. ${ }^{19}$ However, in this study, it was used as a PRO measure of patients' self-reported assessment of their MS disability. The DS scale has been validated against the Expanded Disability Status Scale, a widely used physician-reported measure of disability. ${ }^{20}$ The 7-point DS scale assesses an MS patient's level of disability with the following categories: DS $0=$ normal; DS $1=$ mild disability, mild symptoms or signs; DS $2=$ moderate disability, visible abnormality of gait; DS $3=$ early cane, intermittent use of cane; DS 4 = late cane, cane-dependent; DS $5=$ bilateral support; DS $6=$ confined to wheelchair; and $\mathrm{U}=$ unclassifiable.

\section{Statistical analyses}

Baseline characteristics were summarized using descriptive statistics. Change from baseline (CFB) at years 1, 2, and 3 for relevant outcome measures was examined in patients who had completed at least 3 years of natalizumab treatment. An analysis of covariance was used to evaluate CFB after adjusting for baseline score of the PRO being assessed, DS, FS, number of comorbidities reported, years since MS diagnosis, and age at baseline.

For analyses of SF-12v2, MSIS-29, and TSQM-9 scores, the overall population was stratified by median baseline DS (0-2 or 3-6), median years since MS diagnosis at baseline ( $\leq 10$ years or $>10$ years), and median age at baseline ( $\leq 48$ years old or $>48$ years old).

\section{Results}

\section{Demographic information}

A total of 333 patients met eligibility criteria, remained on natalizumab for at least 1 year, and had completed all three surveys during the first year of treatment (Figure 1). At 2 years, 227 patients had completed the survey, 195 of whom were still on natalizumab, and at 3 years, 155 patients had completed the survey, 120 of whom were still on natalizumab. Reasons for discontinuation of natalizumab were not collected in this study. Patients without a

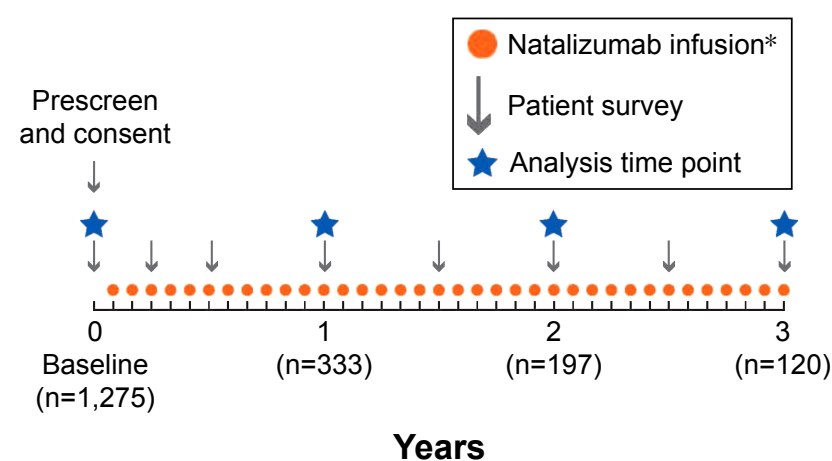

Figure I Longitudinal study design. *One natalizumab infusion every 4 weeks. 
Table I Baseline demographics and disease characteristics of patients who completed $\geq 3$ years of natalizumab treatment stratified by baseline DS, years since MS diagnosis, and age

\begin{tabular}{|c|c|c|c|c|c|c|c|}
\hline Characteristic & $\begin{array}{l}\text { Baseline } \\
\text { DS 0-2 } \\
(n=59)\end{array}$ & $\begin{array}{l}\text { Baseline } \\
\text { DS 3-6 } \\
(n=60)\end{array}$ & $\begin{array}{l}\leq 10 \text { years since } \\
\text { MS diagnosis } \\
(n=68)\end{array}$ & $\begin{array}{l}>10 \text { years since } \\
\text { MS diagnosis } \\
(n=5 I)\end{array}$ & $\begin{array}{l}\leq 48 \text { years } \\
\text { old }(n=64)\end{array}$ & $\begin{array}{l}>48 \text { years } \\
\text { old }(n=56)\end{array}$ & $\begin{array}{l}\text { Total } \\
(\mathbf{N}=\mid \mathbf{2 0}) *\end{array}$ \\
\hline Age, mean (SD) (years) & $44(10.0)$ & $51(9.0)$ & $46(10.7)$ & $50(8.3)$ & $40(7.1)$ & $56(5.0)$ & $48(10.1)$ \\
\hline Sex, female, n (\%) & $50(84.7)$ & $41(68.3)$ & $52(76.5)$ & $40(78.4)$ & $47(73.4)$ & $45(80.4)$ & $92(76.7)$ \\
\hline \multicolumn{8}{|l|}{ Ethnicity, n (\%) } \\
\hline Caucasian or white & $50(84.7)$ & $51(85.0)$ & $53(77.9)$ & $48(94.1)$ & $51(79.7)$ & $51(91.1)$ & $102(85.0)$ \\
\hline African American or black & $6(10.2)$ & $7(11.7)$ & II (I6.2) & $2(3.9)$ & $10(15.6)$ & $3(5.4)$ & $13(10.8)$ \\
\hline American Indian or Alaskan native & $0(0)$ & $\mathrm{I}(\mathrm{I} .7)$ & I (I.5) & $0(0)$ & $0(0)$ & $\mathrm{I}(\mathrm{I} .8)$ & $\mathrm{I}(0.8)$ \\
\hline Mixed & $\mathrm{I}(\mathrm{I} .7)$ & $\mathrm{I}(\mathrm{I} .7)$ & $\mathrm{I}(\mathrm{I} .5)$ & $\mathrm{I}(2.0)$ & $\mathrm{I}(\mathrm{I} .6)$ & $\mathrm{I}(\mathrm{l} .8)$ & $2(1.7)$ \\
\hline Other & $2(3.4)$ & $0(0)$ & $2(2.9)$ & $0(0)$ & $2(3.1)$ & $0(0)$ & $2(1.7)$ \\
\hline
\end{tabular}

Notes: *Information on DS and time since MS diagnosis was missing for one patient. This patient was included in the total population but was excluded from subgroup analyses.

Abbreviations: DS, Disease Steps; MS, multiple sclerosis; SD, standard deviation.

completed survey either were contacted but did not provide a survey ( $\mathrm{n}=65$ at year $2 ; \mathrm{n}=51$ at year 3 ) or could not be contacted $(\mathrm{n}=41$ at year $2 ; \mathrm{n}=21$ at year 3$)$. Only patients with at least 3 years on natalizumab were included in PRO analyses.

Demographic characteristics of patients with at least 3 years of natalizumab treatment are shown in Table 1, and reported comorbidities are shown in Table S1. At baseline, these patients had a median (min, max) DS score of $3(0,6)$, a median (min, max) of time since MS diagnosis of $10(0,32)$ years, and a median $(\min , \max )$ age of 48 $(23,70)$ years (Table 1$)$. Of the 120 patients, 117 (97.5\%) had received a disease-modifying therapy prior to natalizumab initiation.

The baseline demographics, disease characteristics, and PRO scores of patients who completed 3 years in the study were similar to those who had completed the first year of the study but did not remain in the study through year 3 (Tables S2 and S3).

\section{SF-12v2}

SF-12v2 PCS scores increased significantly at 2 and 3 years (adjusted CFB: $2.33[P<0.05]$ and $2.87[P<0.01]$, respectively), indicating improvement in physical HRQoL (Figure 2A). From baseline to year 3, the mean PCS score increased by $8 \%$ (from 34.1 to 36.9 ). In patients with baseline DS 0-2, significant improvement was observed in mean PCS score from baseline to the third year of natalizumab treatment (adjusted CFB: $3.05[P<0.05]$; Figure 2B). For patients with greater disability at baseline (DS 3-6), the CFB was numerically higher at all time points, although these changes were not significant. Similarly, patients with $\leq 10$ years since diagnosis had significant score increases from baseline at years 2 and 3, whereas scores

$0.98 \quad 2.33^{*} \quad 2.87^{\dagger}$

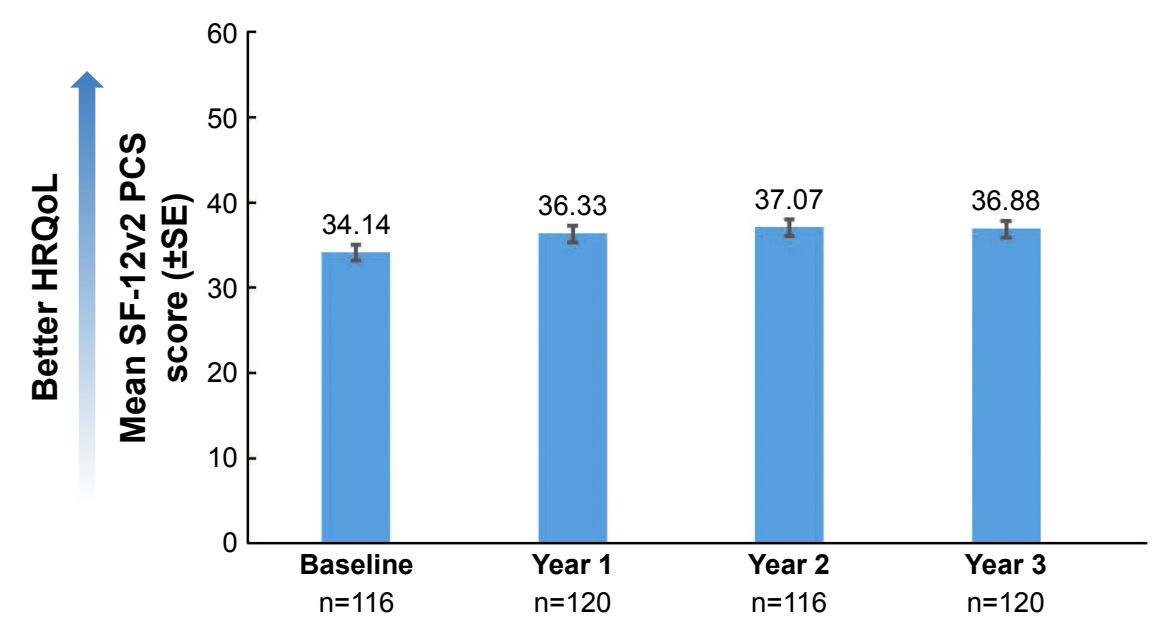

Figure 2 (Continued) 


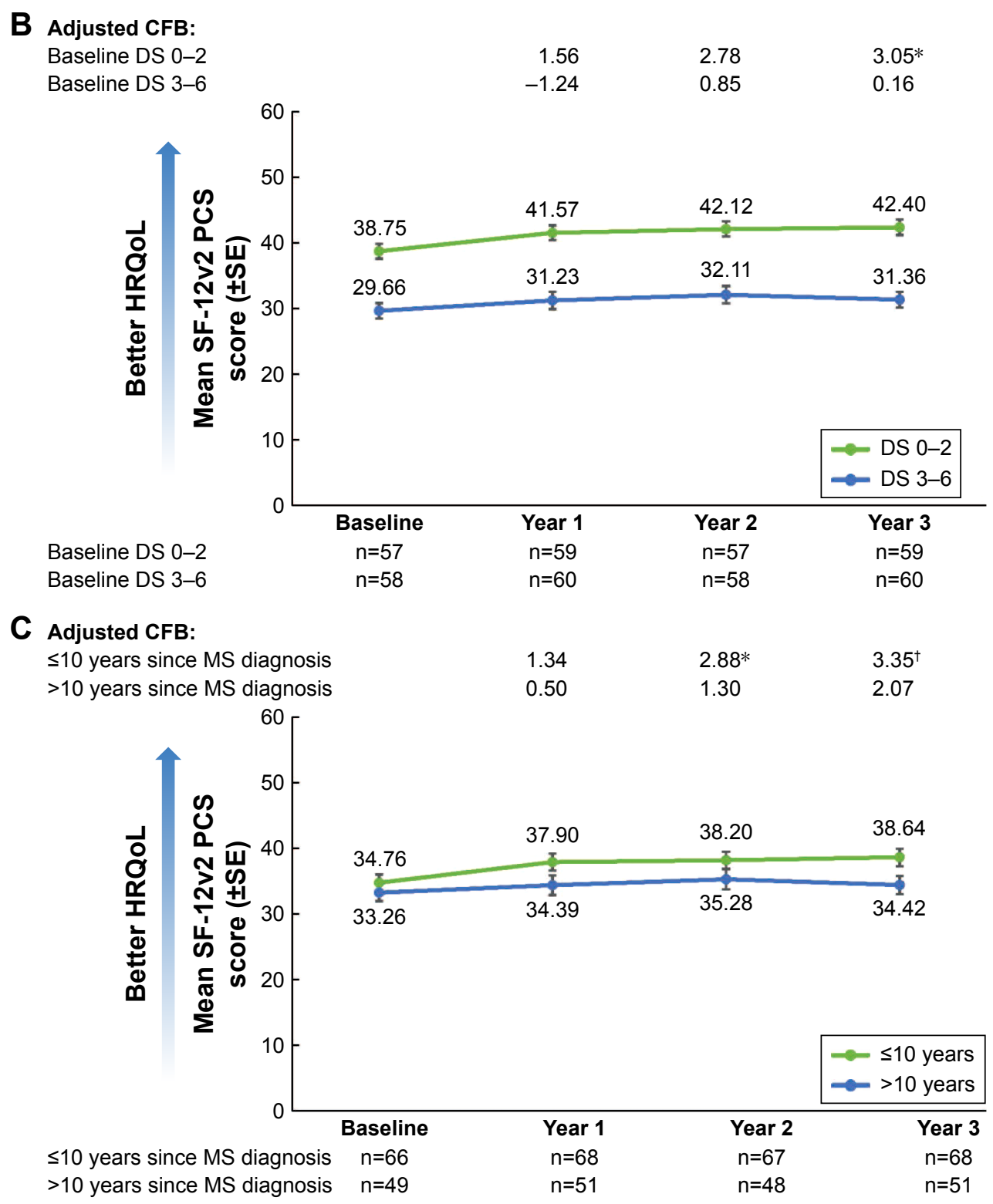

Figure 2 SF-12v2 PCS scores over 3 years (A) in the overall population, (B) stratified by DS at baseline, and (C) stratified by years since MS disease diagnosis. Patients with missing data were excluded from the analysis at that time point. For adjusted mean CFB: $* P<0.05 ;+P<0.01$.

Abbreviations: CFB, change from baseline; DS, Disease Steps; HRQoL, health-related quality of life; MS, multiple sclerosis; PCS, Physical Component Summary; SE, standard error; SF-12v2, Short Form-12 Version 2.

remained stable among patients with $>10$ years since MS diagnosis (Figure 2C). Among patients $\leq 48$ years old, PCS scores increased significantly from baseline to years 2 and 3 (adjusted CFB: $3.15[P<0.05]$ and $3.42[P<0.01]$, respectively), whereas CFBs did not reach statistical significance for patients aged $>48$ years.

Furthermore, overall SF-12v2 MCS scores increased significantly from baseline to years 1, 2, and 3 (adjusted CFB: $5.20[P<0.001], 5.89[P<0.0001]$, and $3.75[P<0.01]$, respectively; Figure 3A). Mean MCS score increased by $9 \%$ from baseline to year 3. Significant improvement from baseline in mean MCS score was seen at 1 and 2 years in patients with DS 0-2 and at 1, 2, and 3 years in patients with DS 3-6 (Figure 3B). Moreover, the improvement from baseline was significant at years 1,2 , and 3 for patients with $\leq 10$ years since MS diagnosis and at years 1 and 2 for patients with $>10$ years since MS diagnosis (Figure 3C). The increase in MCS score from baseline was significant during the first 2 years of treatment for younger patients (aged $\leq 48$ years; adjusted CFB: $4.54[P<0.01]$ and $6.57[P<0.0001]$ for years 1 and 2 , respectively) and during all 3 years of treatment for older patients (aged $>48$ years; adjusted CFB: 5.67 
$[P<0.01], 5.68[P<0.001]$, and $5.32[P<0.01]$ for years 1,2 , and 3 , respectively).

\section{MSIS-29}

Significant decreases from baseline in overall mean MSIS-29 physical score, indicating less impact of MS on patients' lives, were observed at years 1, 2, and 3 (Figure 4A). Mean MSIS-29 physical score declined by $18 \%$ from baseline to year 3. Adjusted CFBs were significant at each of the three yearly milestones for patients with baseline DS scores of 0-2 but did not reach statistical significance for those with baseline DS scores of 3-6 (Figure 4B). Patients with $\leq 10$ years since MS diagnosis exhibited a significant decrease in scores at 1,2 , and 3 years, and those with $>10$ years since MS diagnosis exhibited significant decreases at 2 and 3 years
(Figure 4C). Younger patients had significant adjusted CFBs at each of the 3 years $(-5.42[P<0.01],-8.41[P<0.001]$, and $-6.83[P<0.001]$ at years 1,2 , and 3 , respectively); for older patients, adjusted CFBs were significant at year 1 $(-6.09[P<0.01])$ and year $3(-8.12[P<0.01])$.

The overall MSIS-29 psychological score also decreased significantly from baseline at years 1, 2, and 3 (adjusted CFB: $-9.50,-10.12$, and -8.72, respectively [each $P<0.0001$ ]; Figure 5A). At year 3, the mean MSIS-29 psychological score had decreased from baseline by $22 \%$. Furthermore, scores decreased significantly from baseline among patients classified by disability level or time since MS diagnosis (Figure 5B and C). Similarly, both younger and older patients reported psychological score improvements at all 3 years (adjusted CFB for patients $\leq 48$ years old: $-8.70,-12.67$, and -8.70

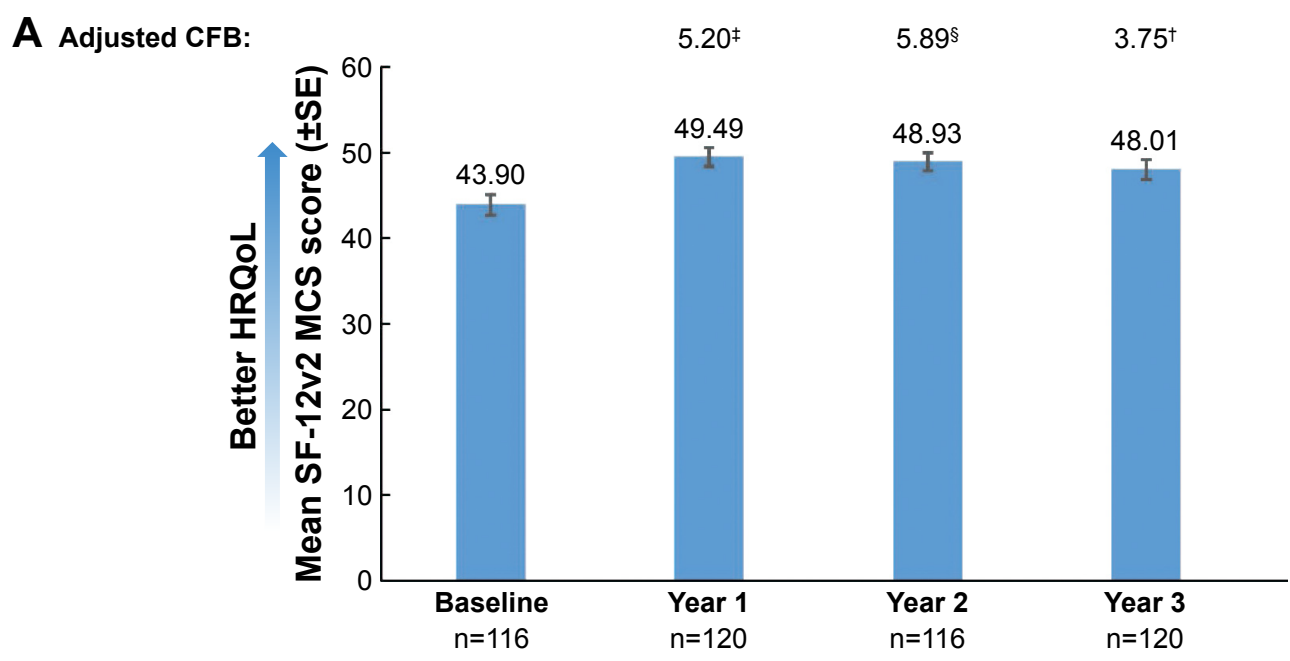

\section{B Adjusted CFB:}

Baseline DS 0-2

Baseline DS 3-6

\subsection{3*}

$6.87 \S$

$6.25^{\ddagger}$

$7.19 \S$

3.15

足

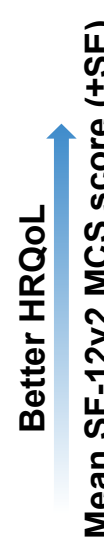

Baseline DS 0-2

Baseline DS 3-6

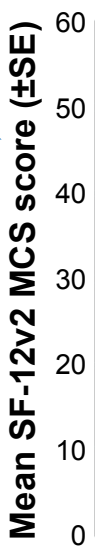

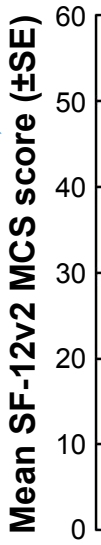

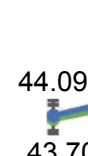

43.70

49.09

$5.59 \ddagger$

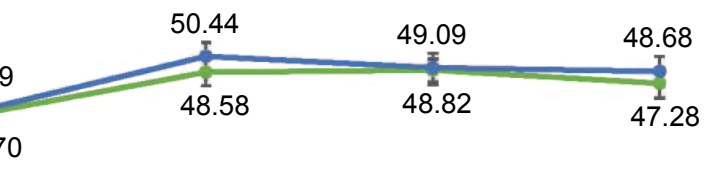

(1)

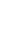
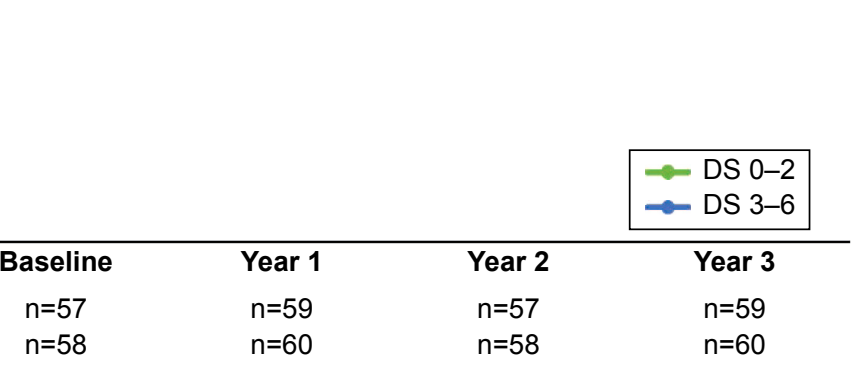

Figure 3 (Continued) 


\section{Adjusted CFB:}

$\leq 10$ years since MS diagnosis

$>10$ years since MS diagnosis

$\begin{array}{lll}4.74^{\dagger} & 6.07^{\ddagger} & 4.33^{*} \\ 6.05^{\dagger} & 5.73^{\dagger} & 3.11\end{array}$

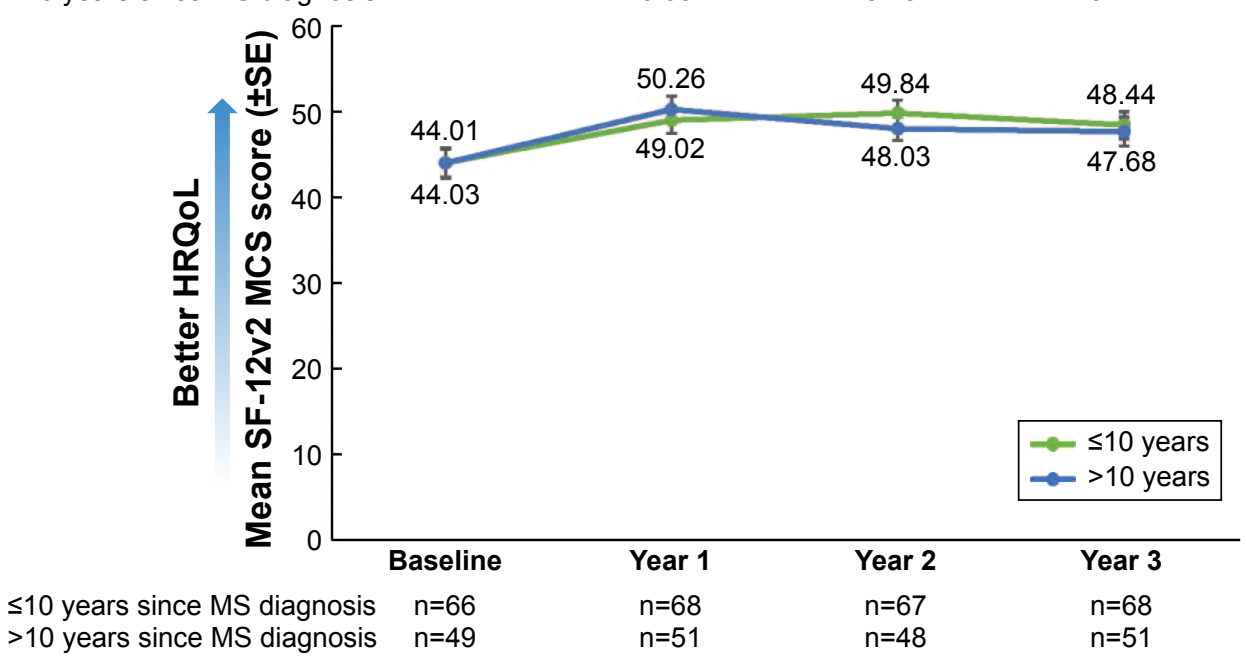

Figure 3 SF-12v2 MCS scores over 3 years (A) in the overall population, (B) stratified by DS at baseline, and (C) stratified by years since MS diagnosis. For adjusted mean CFB: $* P<0.05 ;+P<0.01 ; \neq P<0.001 ; \$ P<0.0001$.

Abbreviations: CFB, change from baseline; DS, Disease Steps; HRQoL, health-related quality of life; MCS, Mental Component Summary; MS, multiple sclerosis; SE, standard error; SF-12v2, Short Form-12 Version 2.

for years 1,2 , and 3 , respectively [each $P<0.001$ ]; adjusted CFB for patients $>48$ years old: $-11.96,-9.37$, and -10.18 for years 1, 2, and 3, respectively [each $P<0.001$ ]).

\section{TSQM-9}

A statistically significant increase was observed in mean effectiveness, convenience, and global satisfaction scores from baseline to 1 year (adjusted CFB: 30.29, 18.16, and 16.13, respectively [each $P<0.0001]$ ). TSQM-9 scores at baseline reflect satisfaction with treatment prior to natalizumab and ranged from 45.88 to 67.38 (out of 100). By year 1, scores ranged from 79.09 to 84.59 , representing increases from baseline of $72 \%$ for effectiveness, $31 \%$ for convenience, and $26 \%$ for global satisfaction. High levels of satisfaction (scores $>80$ out of 100) were maintained at years 2 and 3 (Figure 6). Significant increases from baseline in TSQM-9 subscale scores were observed at years 1, 2, and 3 regardless of baseline disease level, years since MS diagnosis, or age (Table 2).

\section{Discussion}

In patients with MS who were treated with natalizumab for at least 3 years in clinical practice, both general and

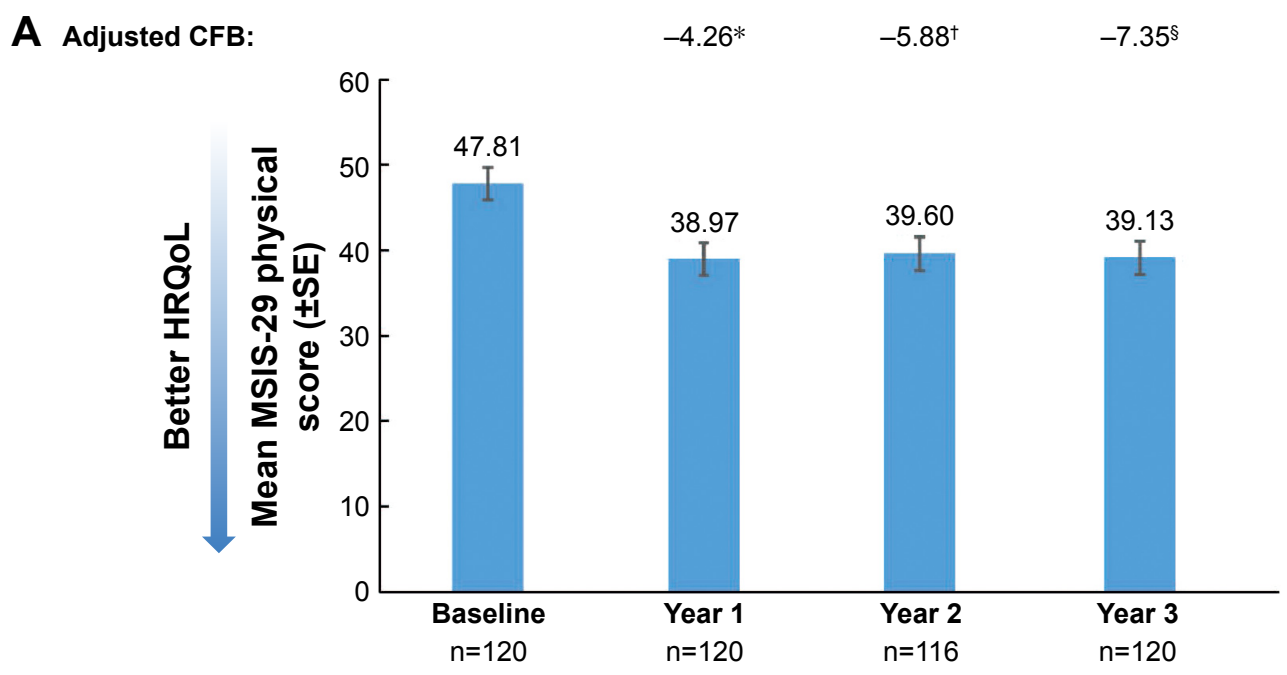

Figure 4 (Continued) 
B Adjusted CFB:

Baseline DS 0-2

Baseline DS 3-6

$-6$

$\begin{array}{llll}-6.19^{*} & -8.13^{\dagger} & -7.60^{\dagger} \\ -3.77 & -4.12 & -3.75\end{array}$

Baseline DS 0-2

Baseline DS 3-6

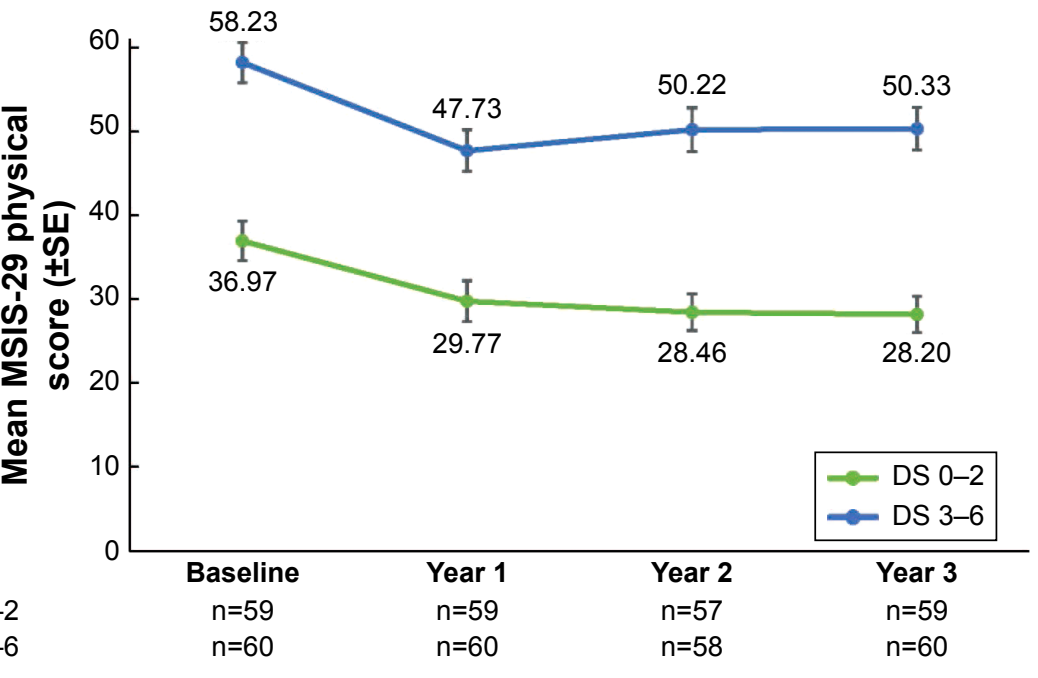

C Adjusted CFB:

$\leq 10$ years since MS diagnosis

$>10$ years since MS diagnosis

$\begin{array}{lll}-4.50^{*} & -5.73^{*} & -7.34^{\ddagger} \\ -4.17 & -6.09^{*} & -7.38^{\dagger}\end{array}$

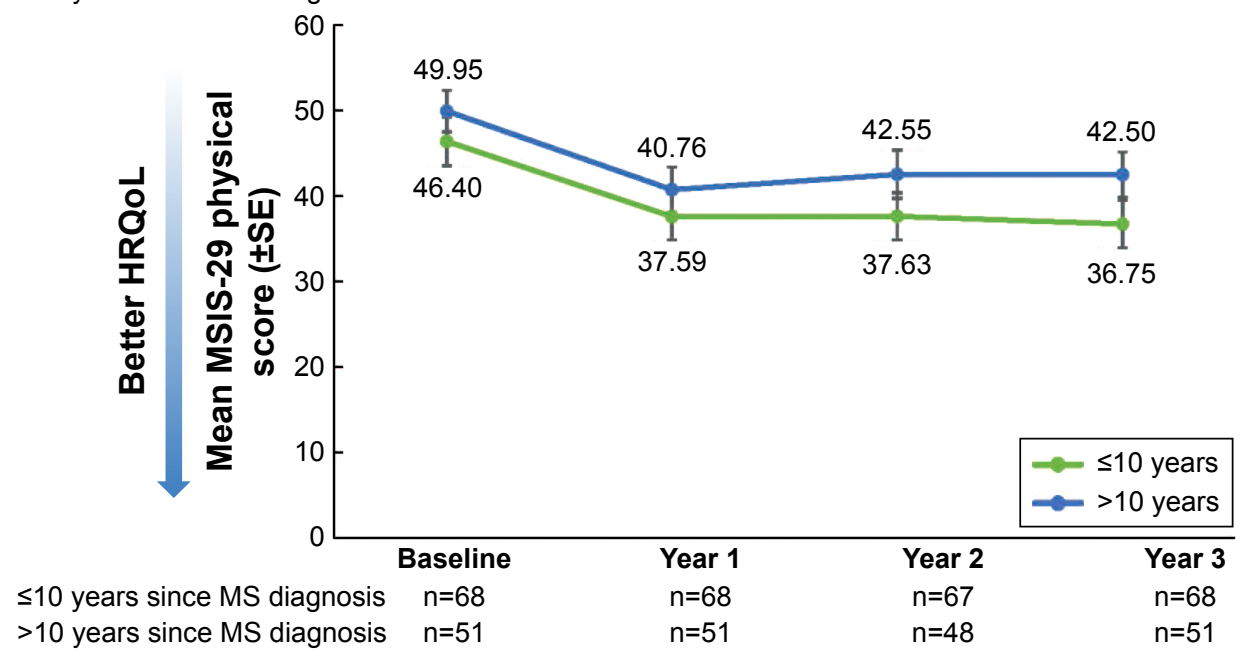

Figure 4 MSIS-29 physical scores over 3 years (A) in the overall population, (B) stratified by DS at baseline, and (C) stratified by years since MS diagnosis. For adjusted mean CFB: $* P<0.05 ;{ }^{\dagger} P<0.01 ; \ddagger P<0.001 ; \$ P<0.000$ I.

Abbreviations: CFB, change from baseline; DS, Disease Steps; HRQoL, health-related quality of life; MS, multiple sclerosis; MSIS-29, Multiple Sclerosis Impact Scale; $\mathrm{SE}$, standard error.

disease-specific measures of HRQoL showed significant improvement over time. These improvements were more dramatic in patients with a lower level of disability at baseline. Over the 3 years of this study, patients with lower baseline physical disability (DS 0-2) showed significant improvement in physical HRQoL by exhibiting increases in SF-12v2 PCS scores and decreases in MSIS-29 physical scores. Although trending toward improved scores, adjusted CFBs in these physical HRQoL measures were not statistically significant in patients with higher baseline physical disability (DS 3-6). These results demonstrate that patients with less physical disability also experience a greater treatment effect on HRQoL than those with greater disability. Furthermore, younger patients ( $\leq 48$ years old) and patients with $\leq 10$ years since diagnosis had significant improvements in SF-12v2 PCS scores, whereas scores for patients $>48$ years old or with $>10$ years since diagnosis did not show a significant change over time. Taken together, these results underscore the importance of treating patients early in the disease course, before the accumulation of physical disability. This finding is in line with previous reports demonstrating the benefits of initiating treatment earlier in the MS disease course. ${ }^{21-23}$ 
On measures of mental and psychological HRQoL, patients experienced a mean improvement over 3 years of natalizumab use. During the first 2 years, these improvements occurred regardless of baseline disease severity, time since diagnosis with MS, or age. Using the MSIS-29 psychological score, significant improvements from baseline were seen regardless of baseline disease severity, time since diagnosis, or age. These results suggest that natalizumab treatment has a beneficial effect on mental and psychological HRQoL in MS patients regardless of their baseline level of functional disability.

These data on the benefit of natalizumab on HRQoL are supported by data from clinical trials. In AFFIRM, patients treated with natalizumab for 2 years exhibited significantly greater improvements in SF-36 PCS and MCS between baseline and 2 years than those treated with placebo. ${ }^{5}$ Significantly greater improvements were also reported on six of the eight individual scales on the SF-36. In the SENTINEL trial, patients treated with a combination of natalizumab and interferon beta-1a for 2 years had significantly improved scores on five of the eight SF-36 scales compared with those treated with interferon beta-1a alone. ${ }^{5}$

In addition to the improvements seen in clinical trials, previously published data from the first year of the current study demonstrate that the benefit of natalizumab on HRQoL is seen in the clinical setting. ${ }^{9}$ After 1 year of natalizumab treatment (12 infusions), $79 \%$ and $84 \%$ of patients exhibited an improvement or no change in the SF-12v2 PCS and SF-12v2 MCS, respectively, and $85 \%$ and $86 \%$ of patients reported stable or improved MSIS-29 physical and MSIS-29 psychological component scores, respectively.

\section{A Adjusted CFB:}
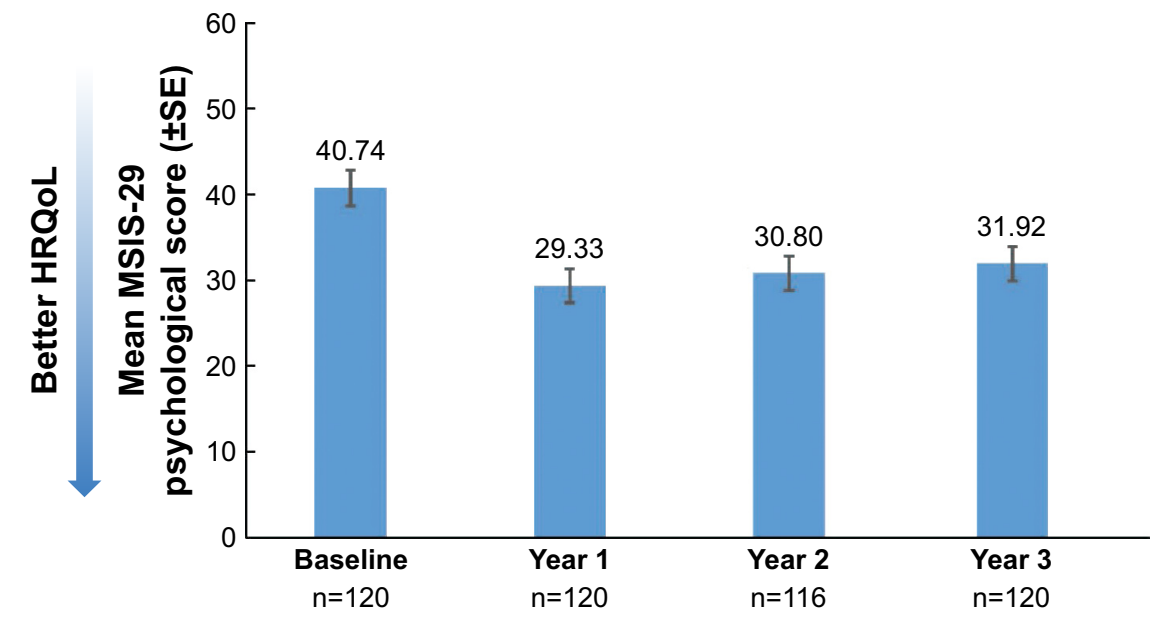

\section{B Adjusted CFB: Baseline DS 0-2 Baseline DS 3-6}

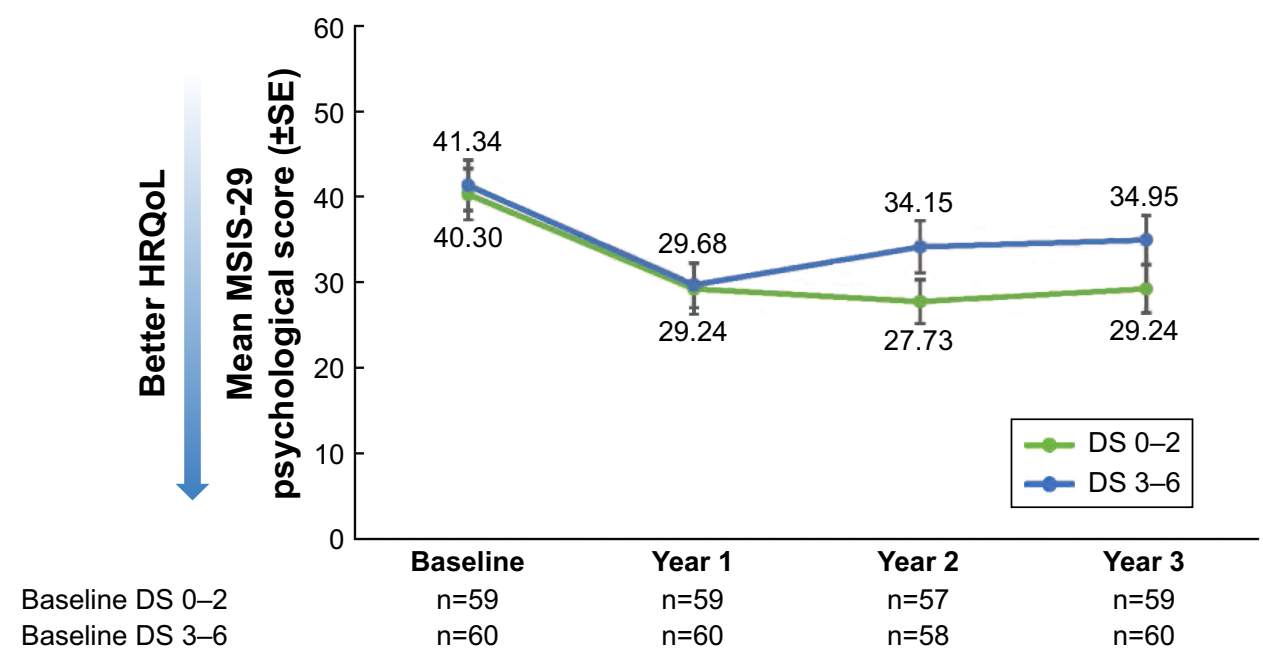

Figure 5 (Continued) 
C Adjusted CFB:

$\leq 10$ years since MS diagnosis $>10$ years since MS diagnosis $\leq 10$ years since MS diagnosis

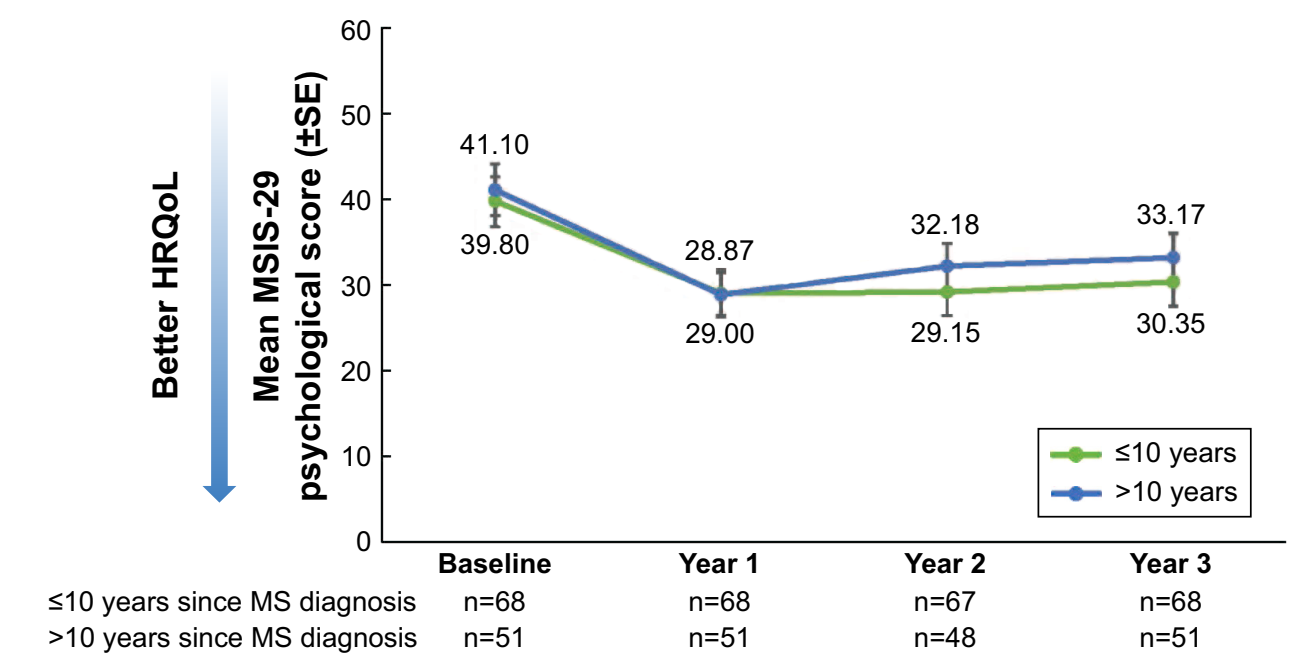

$\begin{array}{rrr}-9.05^{\ddagger} & -9.27^{\ddagger} & -8.77^{\ddagger} \\ -10.60^{\ddagger} & -11.78^{\ddagger} & -9.00^{\dagger}\end{array}$

Figure 5 MSIS-29 psychological scores over 3 years $(\mathbf{A})$ in the overall population, (B) stratified by DS at baseline, and (C) stratified by years since MS diagnosis. For adjusted mean CFB: ${ }^{\dagger} P<0.01 ; \neq P<0.001 ; \$ P<0.0001$.

Abbreviations: CFB, change from baseline; DS, Disease Steps; HRQoL, health-related quality of life; MS, multiple sclerosis; MSIS-29, Multiple Sclerosis Impact Scale; $\mathrm{SE}$, standard error.

In this study, patients reported a significant increase in satisfaction with the effectiveness and convenience of their treatment after starting natalizumab, as well as overall global satisfaction with natalizumab treatment over 3 years. The significant increase from baseline to year 1 suggests that patients were more satisfied with natalizumab than with prior therapies. Furthermore, satisfaction scores $>80$ out of 100 were maintained at years 2 and 3, indicating that patients' satisfaction with natalizumab persisted over time. These results are supported by a previous study comparing patient satisfaction

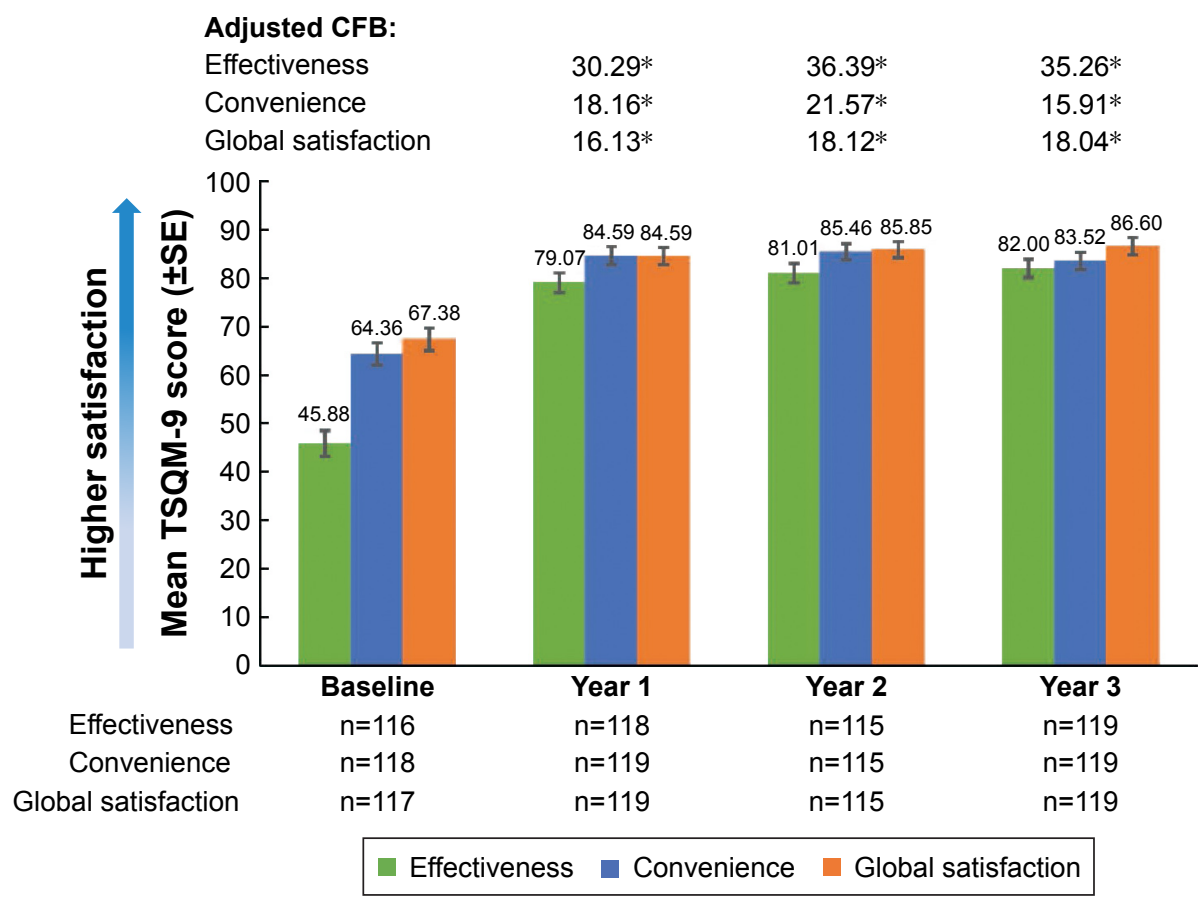

Figure 6 Mean TSQM- 9 treatment satisfaction, effectiveness, and convenience scores in the overall study population that completed $\geq 3$ years of natalizumab treatment. $* P<0.000$ I for all adjusted CFB.

Abbreviations: CFB, change from baseline; SE, standard error; TSQM-9, Treatment Satisfaction Questionnaire for Medication. 
Table 2 Adjusted CFB for TSQM-9 subscale scores after 3 years of natalizumab treatment stratified by baseline DS, years since MS diagnosis, and age

\begin{tabular}{|c|c|c|c|c|c|c|}
\hline & \multicolumn{2}{|c|}{ Baseline DS } & \multicolumn{2}{|c|}{ Time since MS diagnosis } & \multicolumn{2}{|l|}{ Age } \\
\hline & $0-2$ & $3-6$ & $\leq 10$ years & $>10$ years & $\leq 48$ years & $>48$ years \\
\hline \multicolumn{7}{|l|}{ Year I } \\
\hline Effectiveness & $25.36^{\ddagger}$ & $31.18^{\ddagger}$ & $35.15^{\ddagger}$ & $24.45^{\ddagger}$ & $29.8 I^{\ddagger}$ & $30.76^{\ddagger}$ \\
\hline Convenience & $16.32^{\ddagger}$ & $18.10^{\ddagger}$ & $20.45^{\ddagger}$ & $\left.13.9\right|^{\dagger}$ & $17.98^{\ddagger}$ & $16.0 I^{\ddagger}$ \\
\hline Global satisfaction & $12.32^{\dagger}$ & $17.06^{\ddagger}$ & $19.35^{\ddagger}$ & $12.14^{*}$ & $16.67^{\ddagger}$ & $14.80^{\ddagger}$ \\
\hline \multicolumn{7}{|l|}{ Year 2} \\
\hline Effectiveness & $33.3 I^{\ddagger}$ & $34.67^{\ddagger}$ & $35.89 \ddagger$ & $36.95^{\ddagger}$ & $37.18^{\ddagger}$ & $35.50^{\ddagger}$ \\
\hline Convenience & $22.84^{\ddagger}$ & $20.38^{\ddagger}$ & $21.22^{\ddagger}$ & $21.21^{\ddagger}$ & $21.92^{\ddagger}$ & $21.47^{\ddagger}$ \\
\hline Global satisfaction & $16.12^{\ddagger}$ & $18.02^{\ddagger}$ & $17.97^{\ddagger}$ & $18.68^{\ddagger}$ & $19.47^{\ddagger}$ & $17.27^{\ddagger}$ \\
\hline \multicolumn{7}{|l|}{ Year 3} \\
\hline Effectiveness & $37.15^{\ddagger}$ & $31.20^{\ddagger}$ & $35.92^{\ddagger}$ & $34.36^{\ddagger}$ & $34.88^{\ddagger}$ & $37.11^{\ddagger}$ \\
\hline Convenience & $19.94^{\ddagger}$ & $15.08^{\ddagger}$ & $19.85^{\ddagger}$ & $9.78 *$ & $17.04^{\ddagger}$ & $17.82^{\ddagger}$ \\
\hline Global satisfaction & $18.22^{\ddagger}$ & $16.21^{\ddagger}$ & $17.45^{\ddagger}$ & $18.87^{\ddagger}$ & $17.98^{\ddagger}$ & $19.78^{\ddagger}$ \\
\hline
\end{tabular}

Notes: $* P<0.01 ;+P<0.001 ; \neq P<0.0001$.

Abbreviations: CFB, change from baseline; DS, Disease Steps; MS, multiple sclerosis; TSQM-9, Treatment Satisfaction Questionnaire for Medication.

with natalizumab, glatiramer acetate, and interferons, which identified a trend toward greater satisfaction with the effectiveness of natalizumab than with the effectiveness of the other therapies. Furthermore, patients reported significantly greater satisfaction with the convenience of natalizumab treatment than with that of other therapies considered. ${ }^{24}$ Although natalizumab treatment requires monthly visits to an infusion center, patients reported satisfaction with the convenience of natalizumab in both the previous ${ }^{24}$ and current studies.

This study had several limitations. Because the surveys were conducted every 6 months, some PRO assessments may have been affected by recall bias. In addition, patients with less improvement and treatment satisfaction are less likely to remain on natalizumab; therefore, including only patients with $\geq 3$ years of natalizumab treatment may have introduced selection bias. The 1-year analysis of this population included 333 patients, but only 120 (36\%) of those patients completed $\geq 3$ years of treatment. Reasons for dropout were not assessed. This was a single-arm observational study with no control group for comparison. However, previous studies have shown that patients with MS experience HRQoL worsening over time; ${ }^{2,3}$ therefore, the improvements observed here over 3 years of treatment suggest a positive effect of natalizumab on HRQoL in MS patients over time. Finally, this study only included US patients; therefore, additional research is needed to determine whether improvements in HRQoL and treatment satisfaction similar to those seen here are observed outside the US.

\section{Conclusion}

In this study of RMS patients treated with natalizumab in clinical practice, patients reported improvements in physical and psychological HRQoL and in treatment satisfaction. These improvements were sustained over 3 years in patients with continuous natalizumab treatment, supporting the longterm efficacy of natalizumab in real-world settings. Lower baseline disease activity and earlier treatment were related to better outcomes, indicating the importance of starting natalizumab early in the disease course.

\section{Acknowledgments}

Alison Adams, $\mathrm{PhD}$, of Ashfield Healthcare Communications (Middletown, CT, USA) wrote the first draft of the manuscript based on input from the authors, and Joshua Safran of Ashfield Healthcare Communications copyedited and styled the manuscript.

\section{Author contributions}

JFF, KVN, TV, and CW assisted with data interpretation. JJS participated in the design of the study, development of the survey and data collection procedures, statistical analyses, and interpretation of the data. TN performed the statistical analysis. SSA participated in data collection, analysis, and interpretation. All authors contributed toward data analysis, drafting and critically revising the paper, gave final approval of the version to be published, and agree to be accountable for all aspects of the work.

\section{Disclosure}

This study was funded by Biogen (Cambridge, MA, USA), which also funded Niecko Health Economics for statistical analyses, HealthCore for operationalization of this prospective study, and Ashfield Healthcare Communications for medical writing and editorial support in manuscript 
development. JFF received personal compensation from Biogen, Genzyme, and Teva for consulting, speaking, and scientific advisory boards and received financial support for research activities from Biogen, Genentech-Roche, Genzyme, and Teva. KVN received personal compensation for consulting from Biogen and Janssen. TV received honoraria for serving on scientific advisory boards and for consulting services from AbbVie, Alcimed, the American Academy of Neurology, Carpmaels and Rasford, CB Partners, Celestial Intas Pharmaceuticals Ltd., Compass Learning, Genentech/ Roche, Genzyme, Goodwin Procter, LLP, IMS Consulting Group, Novartis, Oxford Pharmagenesis, Patient-Centered Outcomes Research Institute, Sommer Consulting, Teva Neuroscience, WebMD/Medscape, and Xenoport, Inc. as well as research support from Acorda, Biogen, EMD Serono, Genzyme, Janssen Research \& Development, MedImmune, NIH/NINDS, Ono Pharmaceuticals, Rocky Mountain MS Center, and Teva. JJS is an employee of HealthCore, a research and consulting company. She receives no direct compensation as a result of grants or contracts other than her salary from HealthCore. TN received personal compensation from Biogen for consulting services. SSA was an employee of Biogen at the time of this analysis and is now an employee of Alnylam Pharmaceuticals, which was not in any way associated with this study. $\mathrm{CW}$ is an employee of Biogen and holds stock and/or stock options in Biogen. The authors report no other conflicts of interest in this work.

\section{References}

1. Milo R. Effectiveness of multiple sclerosis treatment with current immunomodulatory drugs. Expert Opin Pharmacother. 2015;16(5):659-673.

2. Miller DM, Weinstock-Guttman B, Bourdette D, You X, Foulds P, Rudick RA. Change in quality of life in patients with relapsing-remitting multiple sclerosis over 2 years in relation to other clinical parameters: results from a trial of intramuscular interferon $\beta$-1a. Mult Scler. 2011; 17(6):734-742.

3. Zwibel HL. Contribution of impaired mobility and general symptoms to the burden of multiple sclerosis. Adv Ther. 2009;26(12):1043-1057.

4. Riazi A, Hobart JC, Lamping DL, et al. Using the SF-36 measure to compare the health impact of multiple sclerosis and Parkinson's disease with normal population health profiles. J Neurol Neurosurg Psychiatry. 2003;74(6):710-714.

5. Rudick RA, Miller D, Hass S, et al. Health-related quality of life in multiple sclerosis: effects of natalizumab. Ann Neurol. 2007;62(4):335-346.

6. Rudick RA, Miller D, Clough JD, Gragg LA, Farmer RG. Quality of life in multiple sclerosis. Comparison with inflammatory bowel disease and rheumatoid arthritis. Arch Neurol. 1992;49(12):1237-1242.
7. Polman CH, O’Connor PW, Havrdova E, et al. A randomized, placebocontrolled trial of natalizumab for relapsing multiple sclerosis. $\mathrm{N} \mathrm{Engl}$ J Med. 2006;354(9):899-910.

8. Phillips JT, Giovannoni G, Lublin FD, et al. Sustained improvement in Expanded Disability Status Scale as a new efficacy measure of neurological change in multiple sclerosis: treatment effects with natalizumab in patients with relapsing multiple sclerosis. Mult Scler. 2011;17(8):970-979.

9. Stephenson JJ, Kern DM, Agarwal SS, et al. Impact of natalizumab on patient-reported outcomes in multiple sclerosis: a longitudinal study. Health Qual Life Outcomes. 2012;10(1):155.

10. Maruish ME, Turner-Bowker DM. A Guide to the Development of Certified Modes of Short Form Survey Administration. Lincoln, RI: QualityMetric Incorporated; 2009.

11. Ware J, Kosinski M, Turner-Bowker D, Gandek B. SF-12v2: How to Score Version 2 of the SF-12 Health Survey. Lincoln, RI: Quality Metric Incorporated; 2002.

12. Norman GR, Sloan JA, Wyrwich KW. Interpretation of changes in health-related quality of life: the remarkable universality of half a standard deviation. Med Care. 2003;41(5):582-592.

13. Hobart J, Lamping D, Fitzpatrick R, Riazi A, Thompson A. The Multiple Sclerosis Impact Scale (MSIS-29): a new patient-based outcome measure. Brain. 2001;124(Pt 5):962-973.

14. McGuigan $\mathrm{C}$, Hutchinson $\mathrm{M}$. The multiple sclerosis impact scale (MSIS-29) is a reliable and sensitive measure. J Neurol Neurosurg Psychiatry. 2004;75(2):266-269.

15. Atkinson MJ, Kumar R, Cappelleri JC, Hass SL. Hierarchical construct validity of the treatment satisfaction questionnaire for medication (TSQM version II) among outpatient pharmacy consumers. Value Health. 2005;8(Supp1 1):S9-S24.

16. Atkinson MJ, Sinha A, Hass SL, et al. Validation of a general measure of treatment satisfaction, the Treatment Satisfaction Questionnaire for Medication (TSQM), using a national panel study of chronic disease. Health Qual Life Outcomes. 2004;2:12.

17. Bharmal M, Payne K, Atkinson MJ, Desrosiers MP, Morisky DE, Gemmen E. Validation of an abbreviated Treatment Satisfaction Questionnaire for Medication (TSQM-9) among patients on antihypertensive medications. Health Qual Life Outcomes. 2009;7:36.

18. Goodin DS. A questionnaire to assess neurological impairment in multiple sclerosis. Mult Scler. 1998;4(5):444-451.

19. Hohol MJ, Orav EJ, Weiner HL. Disease steps in multiple sclerosis: a simple approach to evaluate disease progression. Neurology. 1995; 45(2):251-255.

20. Hohol MJ, Orav EJ, Weiner HL. Disease steps in multiple sclerosis: a longitudinal study comparing disease steps and EDSS to evaluate disease progression. Mult Scler. 1999;5(5):349-354.

21. Kavaliunas A, Manouchehrinia A, Stawiarz L, et al. Importance of early treatment initiation in the clinical course of multiple sclerosis. Mult Scler. Epub October 2016.

22. Prosperini L, Gianni C, Barletta V, et al. Predictors of freedom from disease activity in natalizumab treated-patients with multiple sclerosis. J Neurol Sci. 2012;323(1-2):104-112.

23. Butzkueven H, Kappos L, Pellegrini F, et al. Efficacy and safety of natalizumab in multiple sclerosis: interim observational programme results. J Neurol Neurosurg Psychiatry. 2014;85(11):1190-1197.

24. Glanz BI, Musallam A, Rintell DJ, Chitnis T, Weiner HL, Healy BC. Treatment satisfaction in multiple sclerosis. Int J MS Care. 2014;16(2): $68-75$. 


\section{Supplementary materials}

Table SI Comorbidities in patients who completed 3 years in the study $(\mathrm{N}=120)$

\begin{tabular}{ll}
\hline Comorbidities & $\mathbf{n ~ ( \% )}$ \\
\hline Depression & $39(32.5)$ \\
Hypertension & $27(22.5)$ \\
Dyslipidemia (high cholesterol) & $26(21.7)$ \\
Asthma & $13(10.8)$ \\
Osteoporosis & $11(9.2)$ \\
Diabetes & $8(6.7)$ \\
Rheumatoid arthritis & $7(5.8)$ \\
Coronary artery disease & $4(3.3)$ \\
Cancer & $2(1.7)$ \\
Renal/kidney disease & $1(0.8)$ \\
\hline
\end{tabular}

Table S2 Baseline characteristics of patients who completed 3 years in the study and those who completed $\geq 1$ year but $<3$ years (non-completers)

\begin{tabular}{|c|c|c|c|c|}
\hline Characteristic & $\begin{array}{l}\text { Total } \\
(\mathbf{N}=333)\end{array}$ & $\begin{array}{l}\text { Completers } \\
(n=\mid 20)\end{array}$ & $\begin{array}{l}\text { Non-completers } \\
(n=2 \mid 3)\end{array}$ & $\begin{array}{l}P \text {-value (completers vs } \\
\text { non-completers)* }\end{array}$ \\
\hline Sex, female, n (\%) & $260(78.1)$ & $92(76.7)$ & $168(64.6)$ & 0.68 \\
\hline \multicolumn{5}{|l|}{ Ethnicity, n (\%) } \\
\hline Caucasian or white & $292(87.7)$ & $102(85.0)$ & $190(89.2)$ & 0.631 \\
\hline African American or black & $27(8.1)$ & $13(10.8)$ & $14(6.6)$ & \\
\hline American Indian or Alaskan native & $2(0.6)$ & $\mathrm{I}(0.8)$ & $I(0.5)$ & \\
\hline Asian & $2(0.6)$ & $0(0)$ & $2(0.9)$ & \\
\hline Mixed & $4(1.2)$ & $2(1.7)$ & $2(0.9)$ & \\
\hline Other & $6(1.8)$ & $2(1.7)$ & $4(1.9)$ & \\
\hline \multicolumn{5}{|l|}{ Disease level } \\
\hline DS 0-2 & $167(50.5)^{\dagger}$ & $59(49.6)^{\dagger}$ & $108(50.9)^{\dagger}$ & 0.82 \\
\hline DS 3-6 & $164(49.5)^{\dagger}$ & $60(50.4)^{\dagger}$ & $104(49.1)^{\dagger}$ & \\
\hline \multicolumn{5}{|l|}{ Time since MS diagnosis } \\
\hline$\leq 10$ years & $198(60.0)^{\ddagger}$ & $68(57.1)^{\ddagger}$ & $130(61.6)^{\ddagger}$ & 0.483 \\
\hline$>10$ years & $132(40.0)^{\ddagger}$ & $51(42.9)^{\ddagger}$ & $81(38.4)^{\ddagger}$ & \\
\hline \multicolumn{5}{|l|}{ Age } \\
\hline$\leq 48$ years old & $183(55.0)$ & $64(53.3)$ & $119(55.9)$ & 0.731 \\
\hline$>48$ years old & $150(45.0)$ & $56(46.7)$ & $94(44.1)$ & \\
\hline
\end{tabular}

Notes: *P-value for completers vs non-completers was determined using the Fisher exact test. †Information was available for 331 patients in the overall population

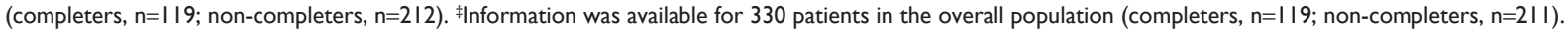

Abbreviations: DS, Disease Steps; MS, multiple sclerosis.

Table S3 Baseline PRO scores of patients who completed 3 years in the study and those who completed $\geq 1$ year but $<3$ years (non-completers)

\begin{tabular}{llll}
\hline $\begin{array}{l}\text { PRO score at baseline, } \\
\text { mean (SE) }\end{array}$ & $\begin{array}{l}\text { Completers } \\
(\mathbf{n}=\mathbf{I} \text { 20) }\end{array}$ & $\begin{array}{l}\text { Non-completers } \\
(\mathbf{n}=\mathbf{2 1 3})\end{array}$ & $\begin{array}{l}\text { P-value (completers vs } \\
\text { non-completers)* }\end{array}$ \\
\hline SF-I2v2 PCS & $34.1(0.92)$ & $34.0(0.78)$ & 0.2864 \\
SF-I2v2 MCS & $43.9(1.19)$ & $42.8(0.79)$ & 0.2771 \\
MSIS-29 physical & $47.8(1.93)^{\dagger}$ & $47.4(1.57)^{\dagger}$ & 0.2845 \\
MSIS-29 psychological & $40.7(2.08)^{\dagger}$ & $42.9(1.53)^{\dagger}$ & 0.2071 \\
\hline
\end{tabular}

Notes: *P-value for completers vs non-completers was determined using ANCOVA adjusted for disease level, functional status, number of comorbidities, years since MS diagnosis, and age. ${ }^{n} \mathrm{n}=116$ for completers; $\mathrm{n}=210$ for non-completers.

Abbreviations: ANCOVA, analysis of covariance; MCS, Mental Component Summary; MS, multiple sclerosis; MSIS-29, Multiple Sclerosis Impact Scale; PCS, Physical Component Summary; PRO, patient-reported outcome; SE, standard error; SF-12v2, Short Form-12 Version 2. 


\section{Publish your work in this journal}

Patient Preference and Adherence is an international, peer-reviewed, open access journal that focuses on the growing importance of patient preference and adherence throughout the therapeutic continuum. Patient satisfaction, acceptability, quality of life, compliance, persistence and their role in developing new therapeutic modalities and compounds to optimize

clinical outcomes for existing disease states are major areas of interest for the journal. This journal has been accepted for indexing on PubMed Central. The manuscript management system is completely online and includes a very quick and fair peer-review system, which is all easy to use. Visit http://www. dovepress.com/testimonials.php to read real quotes from published authors.

Submit your manuscript here: http://www.dovepress.com/patient-preference-and-adherence-journal 